\title{
Cultivation of Innovative Talents and the Integration of Science and Education
}

\author{
Chonghai Xu ${ }^{1,2}$, Guangchun Xiao, ${ }^{1,2}$, Leilei An ${ }^{1,2}$, Jin Du ${ }^{1}$, Lianqin Wang ${ }^{3, *}$ \\ ${ }^{1}$ School of Mechanical \& Automotive Engineering, Qilu University of Technology (Shandong Academy of Sciences), Jinan, P R China \\ ${ }^{2}$ Shandong Institute of Mechanical Design and Research, Jinan, P R China \\ ${ }^{3}$ Logistic Affairs Department, Qilu University of Technology (Shandong Academy of Sciences), Jinan, P R China
}

Email address:

xch@qlu.edu.cn (Chonghai Xu), xgc@qlu.edu.cn (Guangchun Xiao), all@qlu.edu.cn (Leilei An), dj84105@126.com (Jin Du),

sdqywlq@163.com (Lianqin Wang)

*Corresponding author

\section{To cite this article:}

Chonghai Xu, Guangchun Xiao, Leilei An, Jin Du, Lianqin Wang. Cultivation of Innovative Talents and the Integration of Science and Education. Higher Education Research. Vol. 6, No. 2, 2021, pp. 27-39. doi: 10.11648/j.her.20210602.11

Received: March 7, 2021; Accepted: March 27, 2021; Published: April 7, 2021

\begin{abstract}
Science and education integration (SEI) is an important driving force for undergraduate education reform and a vital channel to cultivate innovative and outstanding talent. By means of literature statistical analysis method, the development history of SEI idea for university running and stage characteristics in China are summarized. A comprehensive analysis of the retrieved 385 papers in the field of SEI and innovative talent training was conducted. It suggests that concrete practice of SEI in colleges and universities have expanded the exploration and practice of innovative talent training and achieved remarkable results. It is pointed out that SEI is one of the inevitable choices in the cultivation of innovative talents and the essential characteristics in the new era of higher education. The research status of SEI and innovative talents cultivation are then investigated focusing in specialty construction, curriculum construction, talent cultivation mode, training mode, concept and system mechanisms, etc. The existed problems are discussed in detail, as well as the research and reform directions of SEI for the innovative talent cultivation. This paper illustrates that SEI research and practice is one of the most important concerns in the field of higher education and will play a strong role in promoting high-quality development of higher education.
\end{abstract}

Keywords: Science and Education Integration, Innovative Talents Cultivation, Training Mode, Literature Statistical Analysis

\section{Introduction}

Talent cultivation is the core function of universities, along with scientific research, social service, and cultural inheritance. The German educator Humboldt first proposed the principle of a unification of scientific research and education in the 19th century. He believed that scientific research should be used as a process and method for cultivating individuals. The significant component of his educational thought was to promote an organic combination of education and scientific research in higher education [1]. The Johns Hopkins University, founded by Gilman, is considered to be the beginning of the university era in the United States. The establishment of the graduate school, joint school-enterprise research institute, and the formation of commercially-funded laboratories provided a diversified new system of integration of science and education [2]. At the end of the 20th century, the Boyer Report reflected on the reform of American higher education and proposed a reconstruction of undergraduate teaching, emphasizing the integration of learning by doing.

Since 2000, countries around the world have launched a series of documents for education reform, such as the 2020 Project Vision Report of the United States in 2004, the Action Report on Training 2020 Engineers in 2005, the 21st Century Engineering Challenge Report in 2008, and the Europe 2020 Strategy report in 2010. All documents emphasize the integration of scientific and technological development and talent cultivation, the cooperation between industry and engineering education, the return to practical engineering practices, and a diversified engineering education mode. 
Therefore, it can be concluded that the integration of science and education is an inevitable trend in the development of international higher education [3]. However, there are not ever a comprehensive investigation on the research and development of the integration of science and education in recent years. The purpose of this study is to analyze the development history of the integration of science and education for university running and stage characteristics especially in China with the literature statistical analysis method. After a comprehensive analysis of the research status of innovative talents cultivation and the integration of science and education, the existed problems will then be discussed in detail, as well as the possible research and reform directions of the integration of science and education for the innovative talent cultivation.

\section{Development of Science and Education Integration (SEI) in China}

Research on the integration of science and education can be analyzed from three perspectives. First, through a combination of science and education departments, with "science" referring to the departments of science and technology, and "education" referring to the departments of education; second, through exploring the combination between science and education institutions, with "science" referring to scientific research institutes, and "education" being colleges and universities; the third is an analysis of the combination between science and education activities, with "science" referring to scientific research activities, and "education" referring to educational activities [4].

The understanding of the relationship between "science" and "education" has evolved through several stages. In the early days of the People's Republic of China, China's higher education system followed the Soviet Union's model of "separation of science and education", and the functions of scientific research and teaching were undertaken by scientific research institutes, and colleges and universities, respectively. After the establishment of the University of Science and Technology of China in 1958, colleges and universities started to become an important research force outside of scientific research institutes. However, only a small number of superior disciplines conducted scientific research activities at universities then, and scientific research did not clearly serve to train the students. At this stage, "science" and "teaching" were still in the embryonic stage of instinctive combination.

Since the policy of reform and opening-up was adopted, the positioning of colleges and universities as both educational and scientific research centers has gradually emerged [5]. In 1985, it was made clear that colleges and universities in China should shoulder the dual tasks of training senior professionals and developing science, technology, and culture. Thus, scientific research in colleges and universities was not only required to train talent, but also to promote the development of science and technology. These two basic tasks must be combined and complement each other in order to nurture talent and produce achievements. Since then, the basic idea of the coordinated development of science and education in colleges and universities has been initiated, and "science" and "education" have entered a period of rapid development.

In 2012, the Ministry of Education of China issued Several Opinions on All-Around Improvement of the Higher Education Quality, emphasizing the need to implement the talent-training concept of scientific and educational integration from multiple aspects through new talent training modes, promoting collaborative innovation, and improving the scientific research management system. In August 2012, the Ministry of Education and the Chinese Academy of Sciences launched the implementation of the Action Plan for Talent Cultivation by Collaboration of Science and Education in Beijing. In the same year, the University of Chinese Academy of Sciences was established to explore the cultivation of innovative talent by deepening talent training reform, vigorously promoting collaborative talent cultivation through a combination of science and education, promoting the interaction between scientific research and teaching, and combining scientific research and talent training. In January 2015, the first school of physical sciences that integrated science and education was established at the University of Chinese Academy of Sciences in China. Since then, 12 different disciplines in schools with science and education integration (SEI) have been set up. In September 1999, with the approval of the State Council, the former Northwest Agricultural University, Northwest Forestry College, Institute of Soil and Water Conservation, Chinese Academy of Sciences and Ministry of Water Resources, Northwest Institute of Water Conservancy of the Ministry of Water Resources, Shaanxi Academy of Agricultural Sciences, Shaanxi Academy of Forestry Sciences, Shaanxi Academy of Agricultural Sciences, Shaanxi Academy of Forestry, and the Northwest Institute of Botany of the Chinese Academy of Sciences were merged to form Northwest A\&F University.

In May 2017, the former Qilu University of Technology and the former Shandong Academy of Sciences were integrated to form the new Qilu University of Technology (Shandong Academy of Sciences), which initiated an in-depth exploration of SEI and its practice. The new Qilu University of Technology (Shandong Academy of Sciences) is a significant force in the field of new industrial scientific and technological innovation and talent training in Shandong Province. The university gathers high-quality science and education resources in Shandong Province, implements the management system of university and academy integration, and provides SEI with special features. In a sense, the integration of Qilu University of Technology and Shandong Academy of Sciences is a new exploration of SEI. In February 2019, Taishan Medical University, Shandong Academy of Medical Sciences, Shandong Provincial Hospital, and Shandong Provincial Qianfoshan Hospital were integrated to form the Shandong First Medical University, which was officially established as the Shandong Academy 
of Medical Sciences. Implementation of these policies and concrete practice of SEI in colleges and universities have expanded the exploration and practice of innovative talent training and achieved remarkable results.

\section{Statistical Analysis Based on Literature Related to SEI and Training of Innovative Talent}

In order to accurately grasp the course of SEI research and the training of innovative talent, a comparative analysis was conducted in this paper using the method of literature statistics. By setting different keywords, a search was conducted using the CNKI database. It was found that the first paper exploring SEI and the training of innovative talent was published in 2009 (Figure 1). Jiang et al. [6] reported that the national biological science base of Huazhong Agricultural University actively explored new ideas for training innovative biological talent with agricultural characteristics from the perspective of national strategy, social needs, and school development. After years of reform and practice, and through the combination of science and agriculture and science and education, a "four in one" biological innovative talent training system was constructed, including theoretical teaching, experimental teaching, scientific research and training, management, and a guarantee, and rich achievements were made. There were no relevant papers published for two consecutive years following this research, and then the number of papers increased rapidly to 24 in 2012, and the amount of relevant research has grown significantly since then. During the five years from 2012 to 2016, approximately 20 papers were produced each year. The number has accelerated since 2017, from 38 to 96 in 2020. In 2012, the Ministry of Education and the Chinese Academy of Sciences launched the Action Plan for Talent Cultivation by Collaboration of Science and Education and established the University of the Chinese Academy of Sciences, as well as a new starting point for SEI. Following this, the corresponding research and practice of SEI has grown rapidly. The former Qilu University of Technology and the former Shandong Academy of Sciences were integrated, and the new Qilu University of Technology (Shandong Academy of Sciences) was established in 2017, marking a significant year for the in-depth exploration and practice of SEI.

According to the statistics of discipline classification, among the research papers in the field of SEI, 329 papers were related to higher education, accounting for $85.5 \%$ of the total; 18 papers were related to vocational education, accounting for $4.7 \% ; 15$ papers were related to scientific research management, accounting for $3.9 \%$. It is clear that higher education accounts for the vast majority of published research, which is consistent with SEI understanding and practice of scholars at home and abroad.

According to the statistics of institution classification, 41 institutions have published two or more related research papers, among which the top three are Qilu University of Technology (24), Ningbo University of Technology (16), and the University of Chinese Academy of Sciences (13). Qilu University of Technology and the University of Chinese Academy of Sciences initiated new stages of SEI on two nodes, respectively, so they naturally provide more relevant research and practice. Ningbo University of Technology, as one of the universities selected for the national industry and education integration development project, has been fully integrated into the teaching reform concept of SEI since 2013 and has established a comprehensive pilot of SEI teaching reform in the colleges of architecture and transportation engineering and materials and chemical engineering, which has achieved good results.

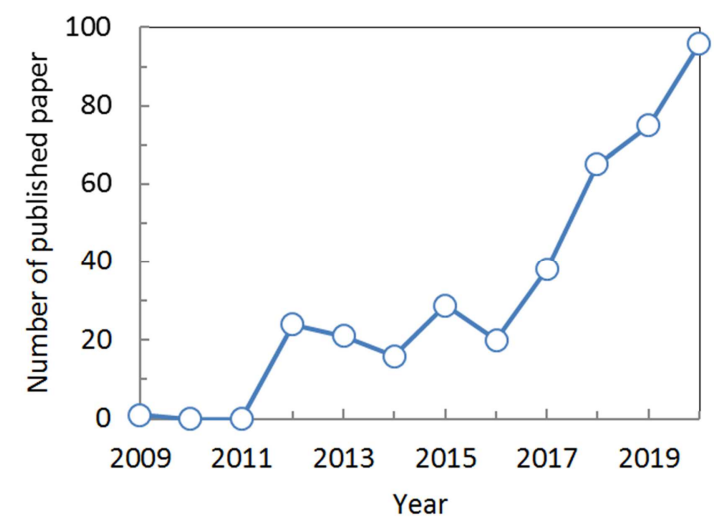

Figure 1. Statistics of related literatures of SEI.

\section{SEI Research and Practice for Training Innovative Talent}

A comprehensive summary and analysis of the retrieved 385 papers in the field of SEI and innovative talent training was conducted. These can be summarized into five aspects: specialty construction, curriculum construction, talent training mode, teaching mode, and the concept and system mechanism (Figure 2). Most of the research on these five aspects has been reported since 2012 and 2013, while the research on curriculum has lagged behind slightly, with research papers available from 2015. Since then, there has been a relatively consistent trend of steady increase. This illustrates that SEI research and practice is one of the most important concerns in the field of higher education and will play a strong role in promoting high-quality development of higher education to some extent.

\subsection{Specialty Construction}

The adjustment of specialty structures has a bearing on the direction, scale, organization, and efficiency of talent training in colleges and universities. Taking Qilu University of Technology as an example, An et al. [7] explored and applied an adjustment of specialty structures in colleges and universities with the background of SEI. The results demonstrate that the new Qilu University of Technology makes use of the advantages of SEI resources to adjust the specialty structures, enhance specialty connotations, and deepen the reform of teaching modes, providing a driving force for further exploration and practice of deepening the 
reform of science and technology and the education system in Shandong province.

$\mathrm{Gu}$ et al. [8] proposed that SEI must be strengthened in order to build first-class specialties in their analysis of SEI in the training of innovative talent in the undergraduate specialty of materials chemistry. They found that discipline resources were being fully utilized, a new curriculum system had been constructed, the curriculum content was updated, and a multi-level teaching and innovation "pyramid" training system had been established, which integrated scientific research into the whole process of undergraduate teaching and significantly improved the comprehensive quality and innovative practice ability of undergraduates.

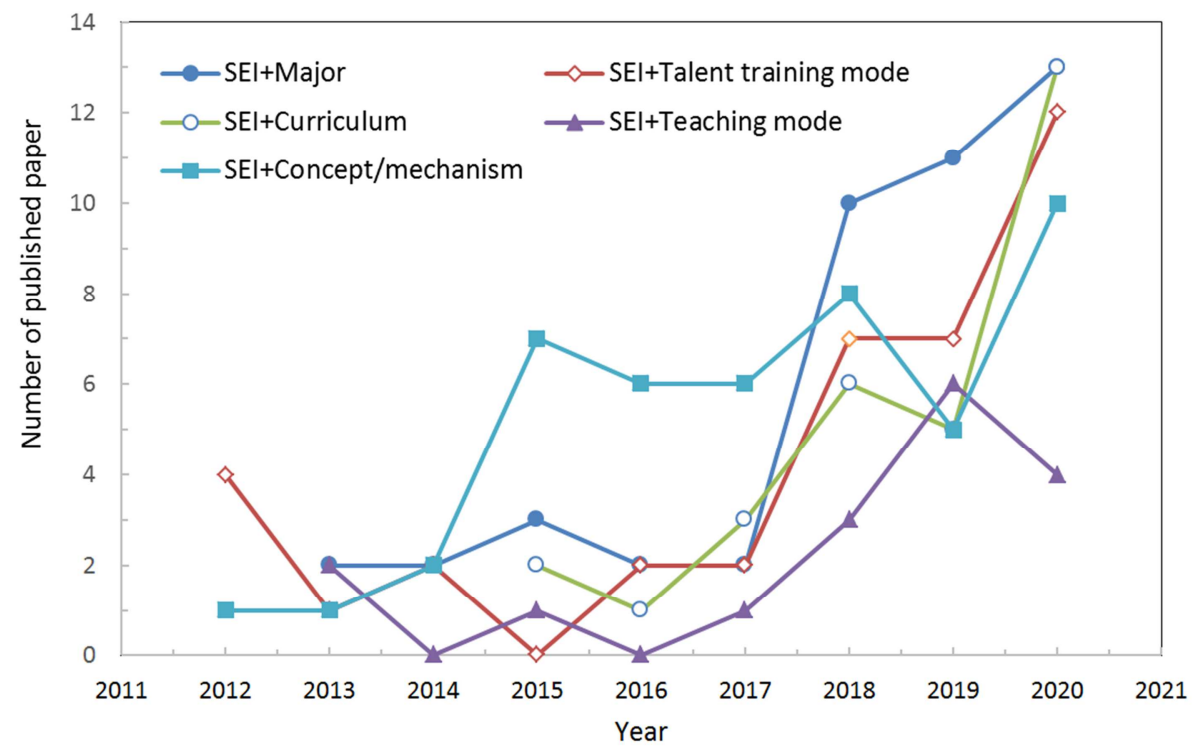

Figure 2. Statistics of related literatures of SEI and innovative talent training.

Some scholars claim that the "integration of science and education, collaborative innovation" is the engine for the development of local universities against the backdrop of reform and connotative development of China's higher education. Talent cultivation by SEI in the application-oriented undergraduate specialty of surveying and mapping was analyzed, the problems during SEI implementation were discussed, a cultivation mode of innovative talents was constructed, and issues that needed to be improved and solved during SEI implementation were presented [9].

$\mathrm{Xu}$ et al. [10] found that SEI often encountered issues in the specific implementation process. Based on a specific analysis of existing problems with the English education specialty in local normal universities, and combined with concepts of SEI, they proposed a scientific and reasonable curriculum system to cultivate students' scientific research awareness and innovation ability, highlighted the characteristics of normal universities, and innovated the assessment mode and performance evaluation standards. They also recommended the practice of cooperation and exchange in basic education, jointly developed scientific research projects, a reform of the scientific research management and assessment system, and the implementation of measures such as the mutual growth of teaching, research, and learning.

Han et al. [11] believed that SEI was an effective way to cultivate high-quality talent. Through a close combination of scientific research and talent cultivation, taking research into new taste sensing technology as an example, they expounded that scientific research enriched the teaching content of the food courses, promoted the innovative education of undergraduates, and provided strong support for the cultivation of high-quality undergraduates in the food specialty field.

Owing to the rapid development of big data, data engineering has become a newly established engineering specialty. Lu et al. [12] investigated and analyzed the current situation of SEI in data engineering specialties. Through analysis of teaching evaluation data and scientific research performance data, the results showed that professional title provided no significant difference in teaching evaluation, and there was no significant difference between teachers with good teaching evaluations and those with poor teaching evaluations. They found that teaching evaluations and the number of years teaching conformed to an S-type function, the teaching years and scientific research performance conformed to the cubic model, paper performance was negatively correlated with teaching evaluation, and project performance was positively correlated with teaching evaluation.

Huang et al. [13] took the new specialty of plant science and technology in Fujian Agriculture and Forestry University as the research object, which practices a talent training mode of deep SEI based on the background, significance, orientation, and goal of professional talent training, and relies on the high-quality teaching experimental platform and practice base of the university. Through practical exploration, they analyzed the preliminary results of the construction of the new specialty, and discussed the necessary improvements required for optimization of the training mode of innovative talent in plant production. 
Kong et al. combined substantive SEI with the cultivation of innovative talent in accordance with the existing talent training mode of forestry and chemical industry from aspects including the current situation of the forestry and chemical industries, formulation of innovative talent training programs, establishment of an innovative curriculum system, exploration of education and teaching modes, and cultivation of innovative teaching. They sought to determine an operation mechanism and education mode of "university-institute talent sharing, resource sharing, discipline co-construction, and talent co-cultivation", and provide theoretical guidance and support for improvement of the quality of innovative talent cultivation under the SEI mode [14].

Yang et al. [15] believe that promoting SEI is the general trend of training students majoring in traditional Chinese medicine. SEI helps to establish an interactive mechanism between teaching and scientific research and to cultivate students' scientific thinking, methods, and attitudes. An SEI teaching model was implemented in the college for one year, achieving good results. It initially realized the effective transformation of scientific research resources into high-quality teaching resources, successfully implemented and practiced "student-centered" teaching concepts, respected the "knowledge-based nature" and "freedom nature" of students, led the students of traditional Chinese medicine to explore the learning, thinking, and application of advanced knowledge, and explored the "creative nature" of students.

Liu et al. found that, regardless of whether the school consciously promoted SEI, there were large quantities of cultivation phenomena and behaviors related to SEI in undergraduate education. According to this study, students are divided into two categories, i.e., "students cultivated by SEI (integration students)" and "students cultivated by non-SEI (non-integration students)" [16]. Through the operational definition of SEI training modes and taking all students majoring in foreign languages in Tonghua Normal University as the research object, this paper draws the conclusion that the SEI training mode can effectively improve the quality of talent cultivation; the learning objectives and understanding of professional prospects of the integration students are more clear; the overall growth rate of knowledge and ability of the integration students is much higher than that of the non-integration students. According to the horizontal comparative evaluation, the integration students also demonstrate a higher evaluation of their self-knowledge and abilities, as well as satisfaction with the school and teachers they come into contact with.

In view of problems with application-oriented electronic information specialties for undergraduates, An et al. [17] proposed that the current requirements of social and economic development for talent training be adapted under the guidance of SEI through classroom education, independent education, and social education, as well as other aspects of teaching reform to achieve the goal of closely combining professional education with the demands of the technology industry and market.

Chemistry, as a traditional specialty in comprehensive colleges and universities, is faced with challenges of backward knowledge, separation from its applications, and graduate difficulties to gain employment in new educational environments and employment situations, and requires urgent reform. Jia et al. [18] took the concept of "SEI, school-enterprise cooperation" to drive comprehensive reform of the traditional chemistry specialty and expand employment channels in Dezhou University. They found that in the limited class hours, students retained strong theoretical and solid foundation characteristics of the specialty, but practical and applied knowledge and training was required to enhance the comprehensive quality and competitiveness of the chemistry major graduates, broaden employment channels, and revitalize the traditional chemistry specialty.

\subsection{Curriculum Construction}

With an increasing amount of research-oriented universities gradually strengthening the guidance and training of freshmen, freshmen seminars have attracted increasingly widespread attention. Such seminars have made an important contribution in integrating the rich scientific research resources and talent training tasks of research-oriented universities and realizing SEI. Seminar features of wide range, small classroom capacity, excellent course content, and flexible teaching methods have been recognized and supported by many teachers and students. However, as there are no standardized teaching evaluation standards or fixed teaching forms, the effect of such seminars can be inconsistent. Based on the practice and experience of freshmen seminar teaching in Renmin University of China, Liang et al. [19] reported on the emerging paradigm of freshmen seminars integrating science and education, whose purpose is to provide more reference value for popularizing and optimizing freshman seminars in colleges and universities.

To meet the training requirements of outstanding navigation talents and further improve the quality of classroom teaching, Chen et al. [20] carried out teaching reform analysis based on the SEI mode for a ship handling course, analyzed the necessity and feasibility of applying the SEI mode, proposed a teaching design scheme for ship handling based on SEI, and explored the implementation effects from aspects including talent training quality, teaching quality, teaching material construction, specialty construction, etc.

In order to strengthen the cultivation of comprehensive quality and innovation abilities of bioengineering students in open experimental teaching using SEI, Fang et al. [21] analyzed the principles of optimization and selection of open experimental projects, and discussed the construction of open experimental courses that could realize the cultivation of innovative talent from the aspects of novelty, professional ability cultivation, simplification and comprehensiveness, individualized teaching, and feasibility in order to improve the experimental curriculum system of the bioengineering specialty, address the deficiency in professional experiments, and improve students' professional skills and talent training qualities, providing a reference for the open experimental teaching of bioengineering. 
Principles of chemical engineering, as one of the compulsory courses for the pharmaceutical engineering specialty, is a course combining theory with practice. Therefore, it is necessary to build a teaching system for the principles of chemical engineering that meets the requirements of higher-level applications and innovative talent training. Zhang et al. [22] applied the concept of "SEI, collaborative talent cultivation" to the teaching process of principles of chemical engineering and explored and practiced a new structure of teaching staff, teaching platforms, design of teaching content, and the penetration of scientific research achievements during the teaching of this course.

Sun et al. [23] investigated how to take full advantage of SEI and solve the problems of insufficient cultivation of students' practical and innovation abilities in the teaching of automobile service engineering. The experimental teaching of automobile service engineering after the merger of Qilu University of Technology and Shandong Academy of Sciences was used as the research object, which was combined with the talent training program and social needs, fully exploiting the resource advantages of both education facilities and considering the requirements of rapid development of the new energy automobile industry for talent. They conducted reform and exploration of the experimental teaching system of this specialty, constructed an experimental curriculum system to take full advantage of both sides, and put forward the development steps of different stages combined with the idea of school development in order to cultivate talent to meet the social needs. This curriculum system is of reference value for the development of specialties with an SEI background or similar specialties.

Zhai et al. state that SEI is the basic system of modern universities. Scientific innovation to meet the demands of industrial technology supports knowledge innovation, which is based on curriculum innovation and promotes talent cultivation in universities. To this end, Qingdao Binhai University used the computer control technology courses of mechanical and electrical majors as an example to carry out curriculum teaching reform from an SEI perspective [24]. According to industrial demand, the course positioning was clarified, the course content was updated carefully to align with industrial developments, teaching methods were reformed using the OBE (outcome-based education) concept for reference, and a scientific innovation platform was jointly built by the university and enterprises. These reforms effectively improved the teaching effect and scientific achievement output and realized the integrated development of scientific and curriculum innovation.

Aiming at the research hotspot of new energy materials, Fang et al. [25] designed a comprehensive experimental project of basic chemistry, i.e., electrochemical oxidation-reduction of the Schiff base, which was integrated into the scientific research. This project reflects the integration and intersection of inorganic, organic, analytical, electrochemical, and other chemical knowledge and covers the experimental content of students' independent research. The students' comprehensive abilities as well as the teaching standard were enhanced through the experimental research of this project.

Han et al. [26] analyzed the connotation and main modes of SEI, expanded on the characteristics of SEI in application-oriented universities that were different from those in research-oriented universities, put forward ideas and steps for the construction of application-oriented practical courses under SEI. They also designed immersive and interactive teaching methods on the basis of transforming scientific research achievements into curriculum resources, pointed out difficulties during the implementation of SEI in application-oriented practical courses, and put forward solution suggestions.

\subsection{Talent Training Mode}

Cultivating innovative talent with SEI has become the core concept and effective path of reform and innovative talent training in China's higher education. Fang et al. [27] deeply analyzed the internal relationship between SEI and the training of innovative talent in application-oriented universities and discussed the internal and external regulation modes of SEI to cultivate innovative talent. They provide an important reference for conducting innovative talent training under SEI in Chinese colleges and universities.

Aiming at the key influencing factors of SEI, Hunan University of Technology carried out useful exploration of the teaching of philosophy and proposed new practices for teaching objectives, organizational structure, teaching methods, and practice. Their practical teaching organization system of "industry-university alliance, base alliance, and training linkage", practical teaching implementation mechanism of "training platform co-construction, teaching plan co-discussion, guiding team co-formation, practice process co-management, and teaching quality co-promotion", and an off-campus practical teaching mode of "three-combination and five-joint" with a high degree of cooperation between the government, university, and enterprises provide a useful reference for Chinese universities to implement SEI [28].

Li et al. [29] systematically explored the connotations, origin, and background of SEI, analyzed the current problems and dilemmas in the concept and practice of SEI, and put forward a strategy and path to promote SEI based on the aspects of policy coordination, governance strategy, system optimization, teaching resources, teaching content, training systems, teachers' professional development, discipline and specialty integration, etc.

Cao et al. [30] state that SEI is an effective way to cultivate innovative talent, but the training mode of SEI and its implementation policy in China still require improvement, which affects the training quality of innovative talent. Therefore, based on the analysis of the connotations of SEI and a summary of issues with the cultivation of innovative talent through SEI in China, the paper puts forward the key points for the construction of an innovative talent training mode of SEI by scientifically positioning the training objectives of innovative talent, firmly establishing the 
concept of SEI, and broadening the training channels of innovative talent. It also proposes guarantee measures for the implementation of innovative talent training modes of SEI from the five aspects of government, universities, teachers, students, and university spirit.

The positive interaction between scientific research and teaching is not only an important way to improve the quality of personnel training, but also one of the important characteristics of colleges and universities. In view of the special background of the engineering discipline and the common difficulties with SEI in colleges and universities, Huang et al. [31] made numerous attempts to formulate a syllabus and training plan by innovating classroom teaching modes, organically connecting the first and second classrooms, and encouraging undergraduates to participate in research projects. The school of light industry and food engineering of Guangxi University organically combines the scientific research process with the teaching process and closely merges the scientific research process with the second classroom. These measures not only significantly cultivate and improve the students' professional practice ability, but also successfully assist the exploration and implementation of SEI innovative projects as well as the cultivation of professional talent.

Liu et al. [32] proposed five talent training modes to promote deep SEI, including an undergraduate tutorial system, output-oriented industry-university cooperation training mode, undergraduate-graduate through talent training mode, innovative talent training mode based on scientific innovation projects, and a student-centered research talent training mode. At present, there are some problems in the talent training modes of higher education, such as simplification of talent training objectives, unscientific curriculum system construction of training schemes, the need to strengthen the substantive implementation of the SEI concept, and system guarantees. By refining the school type and talent training diversion mechanism and optimizing the curriculum system, scientific research can be successfully integrated into classroom teaching and teaching practice systems in order to guide teachers to establish correct SEI concepts and system guarantees to innovate the talent training mode. Through the implementation of an undergraduate tutorial system, China University of Mining and Technology, Beijing, deepened the reform of their talent training mode, promoted deep SEI, and improved the quality of talent training.

Combined with the current situation of training of innovative talent majoring in marine engineering, taking Wuhan University of Technology as an example, He et al. analyzed and discussed the current problems and established a multi-dimensional innovative teaching platform. They used the existing teaching conditions and other resources, combining them with the national SEI key discipline of marine engineering and the Collaborative Innovation Center of Green and Safety Technology for Yangtze River Golden Waterway Green and Safety Technology in order to practice and explore the training mode of innovative talent [33].
Wang et al. [34] implemented the innovative talent training mode and practice of deep SEI in biomedical engineering. By using scientific research achievements to reflect classroom teaching, the discipline advantages of the college were transformed into resources for undergraduate talent training; integration of the biomedical engineering discipline and specialty was constructed, a human, financial and material stability guarantee mechanism for innovative talent training was established, and a project-based learning method was applied to organize the cultivation of innovative talent in a second classroom. It was found that with more undergraduates entering the laboratory to carry out scientific research, the number of winners in various competitions and students applying for postgraduate entrance examinations increased. Data analysis of graduates in recent years by a third-party organization showed that employers had a high satisfaction rate with graduates. Therefore, they believe that deep SEI is a practical talent training mode that can improve students' innovative ability and solve the contradiction between scientific research and teaching.

In view of the problems in the training process of innovative talent in application-oriented engineering, such as the uncoordinated development of practical engineering ability and professional quality, and the disconnection between theoretical teaching and practical teaching, between teaching and scientific research, and between innovation ability and social demand, Li et al. [35] constructed an SEI and project-driven training mode of application-oriented engineering to promote the cultivation of innovative talent.

Application-oriented colleges and universities are an important part of Chinese colleges and universities, which mainly cultivate application-oriented innovative talent to serve local economic and social development. SEI is an effective way to cultivate such talent. However, some problems exist in the promotion process of this training method in application-oriented colleges and universities. Based on this, Yang et al. [36] conducted a detailed analysis and expounded part of their work in the cultivation of application-oriented innovative talent using Chongqing University of Science and Technology as an example to provide some reference for innovative talent training modes in other application-oriented undergraduate colleges and universities.

Taking SEI as the core idea and based on the existing teaching mode, the School of Energy and Power Engineering of Dalian University of Technology and Institute of Engineering Thermophysics of the Chinese Academy of Sciences jointly built the Wu Zhonghua School of Future Energy Technology. Through a construction of the organization, assessment mechanisms, and course teaching systems, and based on effective school operation, the intellectual resources and scientific resources of both sides have been fully exploited and the comprehensive cooperation of both sides has been strengthened in order to cultivate high-end talent with innovative practical and scientific research thinking abilities [37].

Promoting SEI in a comprehensive way represents the 
general trend of undergraduate talent cultivation in China's colleges and universities. However, there are many disadvantages in the cultivation of undergraduate talent with SEI in China's colleges and universities, such as a shortage of undergraduate teaching resources, low integration of teaching and scientific research, and a low conversion rate of scientific research resources to teaching resources. Based on the investigation and analysis of various measures taken by two groups of 38 national collaborative innovation centers in undergraduate talent cultivation, Ding et al. [38] explored the undergraduate talent cultivation mechanism with SEI from the perspective of collaborative innovation to assist in the promotion of the overall development of SEI and improve the quality of undergraduate talent training in China's colleges and universities.

\subsection{Teaching Mode}

SEI combined with teaching theory and practice is the core of teaching mode reform. From Humboldt's combination of scientific research and teaching to Gilman's contributions and Boyer's development, SEI is experiencing an evolution from theory to teaching mode. In this process, some problems have been encountered, such as understanding of SEI teaching modes, the teacher evaluation system and mechanism, allocation of resources, and transformation of scientific research achievements. In view of this, Li et al. [39] put forward four measures and pathways for SEI teaching modes and elaborated on the significance of implementing these measures.

Under the background of new engineering, aiming at the problem of a serious disconnection between theory and practice in engineering mathematics teaching, taking the calculation of eigenvectors in linear algebra as an example, and combined with the latest scientific research achievements, Wang et al. [40] conducted an in-depth exploration of the innovation of university mathematics teaching modes and proposed a new mathematics teaching mode with SEI. They provide a new way of thinking about reform of mathematics teaching in new engineering universities. Teaching practice proves that the idea of scientific research and education can inject new vitality into classroom teaching, stimulate students' learning enthusiasm, and realize the teaching purpose of learning for application.

SEI teaching is a talent training mode for colleges and universities to teach students innovative thinking and endow them with creative and practical abilities. Combining social needs, the educational nature of scientific research, and the training effects of practice, Bai et al. [41] analyzed the importance of SEI teaching for cultivation of innovative practical abilities, encouraged undergraduates to enter the practice space to engage in scientific research and become the subjects and creators of learning activities, and encouraged teachers to introduce high quality scientific research into the classroom teaching process and fully engage in the educational nature of scientific research.

Starting from the impact and challenge of modern network information resources on teachers and students, Han et al. [42] analyzed the current situation that students are faced with more choices and the attraction towards learning from teachers is on the decline in the era of information education used to improve the ability of autonomous learning. They proposed that measures be taken to deeply integrate smartphones, the Internet, and education to improve teachers' information sharing and educating abilities to guide and train students to search and identify information resources to support autonomous learning.

SEI has raised the requirements for synchronous cultivation of the humanistic spirit and scientific research ability of university students. Network technology and the Blackboard (BB) teaching platform have entered the university classroom, bringing new vitality and challenges to teaching reform. Gong et al. [43] made full use of the network and BB platform to maintain the essence of traditional teaching modes, the advantages of science and technology, and the teaching mode of combining classroom teaching and extracurricular guidance to consolidate the basic skills of undergraduates and cultivate their humanistic qualities. They also introduced leading academic issues into the classroom to encourage students to participate in scientific research, develop innovative thinking, and improve their scientific research abilities.

Carrying out SEI and teaching modes of integration of theory and practice in the material specialty is conducive to the improvement of student innovation ability. Through theoretical expansion of a combination of SEI and the material specialty, Lai et al. [44] designed three sets of integrated teaching modes between theory and practice based on SEI and applied them in practice. They then summarized the advantages and issues faced when employing these teaching modes using questionnaire surveys and implementation effect analysis.

As a comprehensive specialty, the design specialty presents an innovative situation for diversified development. In order to promote the cultivation of innovative talent and shoulder the responsibility of innovative talent cultivation, entrepreneurship, and innovation, the design specialty makes full use of modern information technology. Under the guidance of the concept of "integrating teaching with research, integrating science and teaching", Yang et al. [45] reexamined how to promote SEI and explored innovative teaching models to improve the quality of design teaching.

As the basic university concept throughout the development process of modern universities, SEI is indeed the core of modern university education. In order to better realize the concept of "the unity of teaching and scientific research", it is necessary to make changes to traditional teaching. Taking materials science and engineering as an example, Tang et al. [46] promoted the implementation of an inquiry teaching mode with scientific research projects and reformed classroom teaching content and practical teaching in combination with SEI. This is of great practical significance for realizing the combination of scientific research and teaching and helps to achieve the goal of "teaching and learning grow together". 


\subsection{Concept and System Mechanism}

SEI is a concept of university learning which continues to expand despite various challenges. Zhou et al. [5] believe that the idea of SEI has been present from Humboldt's Universität zu Berlin to Gilman's Johns Hopkins University and extends to contemporary research universities. They state that SEI will become the main theme of reform and transformation of higher education worldwide. The cultivation of talent through the collaborative innovation of scientific research and teaching is an important theoretical and practical issue that higher education must face and solve.

The idea of SEI advocates that university teachers must correctly handle the relationship between teaching and scientific research, update teaching content, reform teaching methods, and reposition the goal of undergraduate education. $\mathrm{Qu}$ et al. [47, 48] analyzed 542 questionnaires of different types of university teachers and found that university teachers have a high degree of recognition of the concept of SEI, but the absence of practical motivation, gender, education background, discipline, type of institution, professional title, length of teaching, and whether part-time administrative jobs exist, all influence the concept recognition and practical action of SEI. University teachers' recognition and practice of the concept of SEI also displays an obvious interest-related orientation. Innovating university teachers' management culture, following the interest demands of different university teachers, and establishing a policy guidance mechanism for the integration of teaching and scientific research are suggested solutions for transforming the recognition of SEI as a concept into practical action. Further, based on comparative analysis of the questionnaires carried out by prominent teachers and ordinary teachers in colleges and universities, they found that the understanding and practice of SEI by well-known teachers are barely affected by gender, length of teaching, education background, types of colleges and universities, disciplines, and other factors; on the whole, the concept recognition and practical application of SEI are significantly better than ordinary teachers. However, there is a significant gap between the recognition of SEI as a concept and its practical application by well-known teachers, and there is no obvious advantage in the reform of teaching methods by such teachers. It can be observed that SEI is conducive to the cultivation of high-level teachers, and the efforts and abilities of prominent teachers make them perform better in dealing with the relationship between teaching and scientific research and updating teaching content. However, the absence of organizational culture, the institutional environment, and team building degrades the desire and action of such teachers to reform teaching methods.

According to Zhou et al., students do not welcome advanced teaching ideas because university teaching reform follows the "society-oriented standard" and "knowledge-oriented standard", while ignoring students' interests, opinions, anxieties, and disputes. As important stakeholders, all reforms are futile if students do not act on them. University teaching reform is essentially a political process, and SEI is a teaching reform concept of a "teacher-oriented standard". Zhou et al. [49] designed a questionnaire to investigate the current situation and differences of SEI in undergraduate education and conducted a survey in 21 universities in China. The survey found that there is an attitude difference between university teachers and students towards SEI reform, most students are more willing to participate in research-based learning, but many students are less active in participating in scientific research projects, the implementation of SEI in undergraduate education is not met with optimism, and that students from different backgrounds display behavioral differences in all aspects of SEI. These research results prove the theoretical hypothesis.

SEI is an important driving force for undergraduate education reform and a vital channel for the country to cultivate innovative and outstanding talent. The practical path of implementing SEI includes building an integrated construction and development mode of discipline and specialty, implementing research-based teaching reform of SEI, and improving strong external guarantees and internal incentive mechanisms. Through the implementation of an undergraduate tutorial system, China University of Mining and Technology, Beijing, constructed a talent training mode based on exploration, explored the collaborative mechanism of undergraduate and postgraduate education, improved the sharing and co-construction mode of teaching and research resources, implemented the concept of SEI, and improved the talent training quality [50].

Traditional university education in China was deeply influenced by the former Soviet Union model, and the policy of separating scientific research from education and teaching was implemented. Since China's reform and opening-up, Nanjing University has adhered to the educational concept of high-level research supporting high-level teaching, innovated the talent training mode, and deepened its reform of the curriculum system in order to further enhance the subjectivity of student learning and provide strong support for improving the quality of undergraduate education [51].

SEI is an important concept for the sustainable development of colleges and universities. The integration of scientific research and teaching works to cultivate students' scientific research abilities and improve the comprehensive quality of contemporary college students. Zhong et al. [52] used teachers at the School of Mechanical and Automotive Engineering of Anhui Polytechnic University as a research object and defined the content of SEI from three aspects: teaching contents, teaching methods, and talent training goals through a questionnaire survey. They arranged and counted the survey results by combining the professional title level, education level, age structure, and gender structure and analyzed reasons for the differences between the teachers' concept recognition and practice of SEI. They concluded that teachers in this university recognized the concept of SEI and could achieve a basic level of practice. Meanwhile, in order to encourage university teachers to transform the concept recognition of SEI into specific practical action by combining scientific research and education, the teachers' teaching concept culture 
was innovated, and corresponding policy guidance mechanisms were formulated.

SEI requires a transformation of contemporary higher education ideas and concepts and a deep-seated reform and innovation of talent training modes for modern universities. At present, theoretical and practical research in the field of SEI needs to be further improved. Lin et al. [53] analyzed the development history and connotations of SEI at home and abroad, reform practices and practical difficulties, and the alienation of the combination of science and education and countermeasures, providing some insight for further promoting the transformation of China's higher education and activating the core power of innovative talent training mechanisms.

The relationship between teaching and scientific research is a basic issue in higher education. Zhang et al. [54] believe that in order to expand the role of scientific research and teaching in higher education, a deep penetration of teaching and scientific research in the process of education must be realized. However, in practice, SEI faces challenges including value orientation, teachers, funding policies, and education modes. Therefore, it is necessary to stimulate the enthusiasm of teachers, cultivate the initiative of students, and realize synchronous development of teaching abilities and scientific research. Based on this, they analyzed the path of cultivating the concept of SEI in higher education.

Liu et al. [55] proposed the reconstruction of a first-class undergraduate education under SEI. As SEI is the basic foundation of modern universities and higher education supported and led by scientific research is an essential feature of modern universities, first-class undergraduate education is impossible without SEI. The concept of the SEI system and mechanism runs throughout the entire process of higher education. Attention should thus be paid to the innovation of multiple paths and carriers to eliminate relevant resistance. At the same time, a supporting system and policy of enrollment, academic degree, graduation, incentive, and evaluation is required. A comprehensive transformation of university systems is necessary for SEI to be effectively realized to provide first-class undergraduate education.

At present, the prominent problem in higher education is the absence of an effective integration of teaching and scientific research in colleges and universities to jointly serve talent cultivation. This phenomenon originates from teachers' behavior preference for scientific research that is independent of teaching, which is shaped by the performance evaluation system of managerialism. Zhou et al. [56] proposed that public policies should be adjusted strategically to alter the separation of science and education: first, to change the separation system of science and education and innovate the evaluation mechanism of scientific research; second, to enhance education self-confidence and establish Chinese standards for university evaluation; third, to break the discipline stereotype of "first-class universities and first-class disciplines (double first-class)" construction and promote the integration of disciplines and specialties; fourth, to respect academic professional characteristics and attach importance to peer evaluation and qualitative evaluation; fifth, to abandon the idea of a discipline-oriented standard and set up a student-centered concept.

As the essential feature of research-oriented universities, SEI is the general trend of reform and development of the science and education system in today's world and is a higher education reform that needs to be vigorously advocated for. In practice, however, SEI has not been smoothly implemented, and governance systems and mechanisms are key restrictions. Using the University of Chinese Academy of Sciences as an example [57], the dynamic mechanism of SEI between scientific research institutions and educational institutions and the reasons for governance dilemmas, combined with the exploration and practice of SEI in case universities in recent years was analyzed. It was revealed that organizational change is an effective way to break through the governance dilemma of SEI; that is, to transform the organizational structure, objectives, operation basis, incentives, and culture in order to integrate SEI into organizational structures and operational development mechanisms.

Taking the materials discipline of the University of Chinese Academy of Sciences as an example, Zhang et al. [58] analyzed academic papers jointly published in SCI journals by universities and research institutes and explored SEI from the two dimensions of quantity and quality. They found that there was still room for improvement in the integration of universities and research institutes. This analysis method provides a new way for other institutions to evaluate SEI.

Wang et al. believe that China's higher education has transformed from simple teaching to paying equal attention to science and education, and SEI has gradually developed into a new model of running colleges and universities in China [59]. In this context, China has actively deepened the reform of its higher education system. The higher education system and management mechanisms are experiencing new environmental changes, and the internal governance of colleges and universities is facing new challenges and opportunities. Therefore, it is highly important to realize the modernization of colleges and universities' internal governance structures in this transition period. Based on the current situation of SEI in Shandong province, the author focused on the study of internal governance of colleges and universities in the process of SEI.

The core concept of promoting "double first-class" construction is to promote SEI. Wang et al. [60] summarized the concept of "double first-class" and SEI, identified the existing problems and causes according to the current situation of SEI, put forward relevant suggestions and schemes for its mode and mechanism by exploring the problems in the process of SEI construction, and presented the methods and paths for SEI construction from the aspects of universities, government, and society.

\section{Conclusions}

SEI is an important concept of education and that basic principle of contemporary universities. It includes the 
interaction between scientific research and teaching, the transformation of achievements between scientific research and teaching, and students' participation in scientific research activities. The experience of the University of Canterbury in New Zealand provides helpful insight. Influenced by the education law and academic audit system, the University of Canterbury constructed an innovative system of SEI. For example, SEI was established in the constitution and strategic planning and other major systems and was promoted through core systems such as teacher management and institutional reform [61]. In addition, an organization-wide, multi-form, and explicit practice strategy system was formulated. Like many universities globally, the University of Canterbury has also encountered many challenges in implementing SEI. Despite these issues, the idea of SEI remains a foundational principle of higher education.

The "Integration and Innovation of Science and Education in the Age of Big Science and the 14th International Symposium on Development Strategy of Science and Education" was held in Hangzhou in December 2019. It was sponsored by Zhejiang University and the Education Committee of Chinese Academy of Engineering under the guidance of the Higher Education Department of the Ministry of Education, the China Association of Higher Education, and the Engineering Education Committee of China Association of Higher Education, cosponsored by Research in Higher Education of Engineering, and managed by the Strategic Research Institute of China's Science and Education and the School of Engineers of Zhejiang University. Sessions on SEI and the innovation of basic research and on SEI and innovation of engineering science and technology were held on July 7 . Thoughts on SEI and the construction of world-class universities were shared by educational organizations such as the African Engineering Education Association, Zhejiang University, the University of Chinese Academy of Sciences, the University of Electronic Science and Technology of China, Chongqing University, and industrial companies such as CETHIK Group, the Alibaba Group, and the Huike Group [62]. The participants discussed innovative talent training modes, including the deep integration of "research, engineering and teaching", cross-organization SEI, and research-oriented teaching challenges. Typical cases of cultivating first-class innovative talent through SEI in colleges and universities and enterprises were introduced, and prospects concerning the education mode of science and education collaboration and the integration of industry and learning were discussed from the perspectives of curriculum system construction, curriculum content design, and school-enterprise cooperation, which also pointed out the future development direction for the research and practice of SEI.

In October 2018, the Ministry of Education issued the Opinions on Accelerating the Construction of High-Level Undergraduate Education and Comprehensively Improving the Ability of Talent Training and decided to implement the Six Excellence and One Top-notch Plan 2.0. The document clearly stipulates that a collaborative training mechanism of SEI and mutual promotion should be established in combination with major scientific and technological projects, identifying directions for deepening the research and practice of SEI. It is expected that there will be further innovative research and practice to provide new contributions to the high-quality development of higher education.

\section{Acknowledgements}

This work was supported by The Teaching Reforms Projects for Shandong Provincial Universities (grant No. Z2018S011), The Graduate Education Quality Curriculum Projects of Shandong Province (grant No. 24191302), The Teaching Reforms Projects of Qilu University of Technology (Shandong Academy of Sciences) (grant No. 201801, 201825), The Graduate Education Quality Curriculum Projects of Qilu University of Technology (Shandong Academy of Sciences).

\section{References}

[1] Burton R. Clark, Places of inquiry-research and advanced education in modern university, Berkeley and Los Angeles: University of California press, 1995.

[2] Lin Yanhong, Innovation and Practice in the Concept of Integration of Education and Research-A Case Study of the University of Chinese Academy of Sciences. Research on Graduate Education. 2015 (4): 27-32.

[3] Zou Xiaodong, Han Xu, Yao Wei, Integration of Science and Education: New Normal of University Education. High Engineering Education Research, 2016, (1): 43-50.

[4] Kang Qi, Zhou Huadong, Liang Hongli, Wang Haiyan, On the connotation, essence and path of promoting the integration of science and education. Research on science and technology management, 2013, (12): 212-214+219.

[5] Zhou Guangli, Ma Haiquan, Integration of science and education: The reform and innovation of higher education idea. Research on Higher Education in China, 2012, (8): 15-23.

[6] Jiang Hang, Jin Anjiang, Duan Dejun, Integration of both science and agriculture and science and education for the cultivation of innovative talent of biology, China University Teaching, 2009, (2): 51-53.

[7] An Leilei, Research and practice of the specialty structure adjustment in university under the background of science and education integration-with an example of Qilu University of Technology, Journal of Jinan Vocational College, 2020, (5): 73-75+78

[8] Gu Shaoxuan, Zhu Zhenqi, Lei Liwen, Zhao Chunxia, Xu Qing, Wen Jin, Exploration and practice of science and education integration in the cultivation of innovative talents of Materials Chemistry Education and Teaching Forum. 2019, (46): 128-129.

[9] Zhang Defu, Li Mingna, Wang Wenfu, Research on the Application-oriented University Talent Cultivation for the Specialty of Surveying and Mapping Engineering under the Background of Integration of Science and Education. Surveying and mapping and spatial geographic information, 2020, (5): 61-64. 
[10] Xu Mingli, Study on the talent cultivation of English education specialty in local normal university based on science and education integration, Journal of Lanzhou Institute of Education, 2019, (1): 137-139.

[11] Han Fangkai, Feng Fan, Zhang Dongjing, Duan Tengfei, Xia Qiuxia, Zhang Xingtao, Integration of Research and Teaching Promotes the Cultivation of Undergraduates in Food Specialty-taking the Study of Novel Technology of Taste Sensing as an Example. Shandong Chemical Industry, 2019, (12): 136-137.

[12] Lu Xingiia, Chen Zhirong, Investigation and Analysis of Integration of Science and Education in Data Engineering Specialty. Education and Teaching Forum, 2019, (27): 91-92.

[13] Huang Xueying, Wu Weiren, Lan Tao, Construction and practice of new specialty with the deep integration of science and education, Education Modernization, 2018, (52): 158-160.

[14] Kong Fangong, Cao Shilin, Wang Shoujuan, Zhao Xin, Xia Nannan, Chen Jiachuan, Innovative Talents Education in Chemical Engineering of Forest Production from the Perspective of Integration of Scientific Research and Teaching. Light industry education in China, 2018, (3): 61-64.

[15] Yang Lei, Liu Nuan, The application and practice of integration of science and education in the undergraduate teaching of Traditional Chinese Medicine major, Education Modernization, 2018, (53): 225-227.

[16] Liu Jingping, The empirical analysis of the effect of "science and education integration" in talent cultivation-with an example of foreign language major in Tonghua Normal University, Chinese University Science \& Technology, 2017, (6): 76-77.

[17] An Peng, Investigation and practice of integration of science and education in the electronic information specialties, Computer Education, 2016, (5): 21-23.

[18] Jia Chunxiao, Xin Bingwei, Wang Dunqing, Niu Ping, Comprehensive Reform of Traditional Chemistry Specialty Driven by 'Integration of Science and Teaching, Cooperation of School and Enterprise' in Dezhou University. Journal of Dezhou University, 2015, (6): 8-11.

[19] Liang Xun, Shen Hua, Shao Xiaoye, Liang Bin, Exploration and Practice of Constructing a New Paradigm of Freshman Seminar Integrating Science and Education-Based on a Case Study of Renmin University of China. Journal of Higher Education, 2019, (18): 12-14.

[20] Chen Houzhong, Wong Jianjun, Guo Guoping, Yang Yadong, Design and implement of "Ship manoeuvring" course based on the science and education integration mode, Maritime Education Research, 2018, (1): 27-30.

[21] Fang Haiyan, Lan Wenjun, Study on the Course Construction of Open Experimental Teaching Based on the Integration of Science and Education. Value Engineering, 2018, (28): 276-277.

[22] Zhang Shiming, Chen Yongzheng, Xiong Jun, Exploration and Practice of the Teaching Idea of the Cooperative Education by the Integration of Scientific Research and Teaching in the Principle of Chemical Engineering for the Pharmaceutical Engineering Major. Guangdong Chemical Industry, 2019, (20): 209-211.

[23] Sun Huilai, Liang Yutian, Yang Hui, Zhao Jiajun, The construction of experimental system of automobile majors under the background of science and education integrationwith an example of Qilu University of Technology, University Education, 2020, (1): 64-67.

[24] Zhai Mingge, Meng Qingsen, Xue Bin, The promotion of engineering courses with the integration of science and education-with an example of computer control courses, Chinese University Science \& Technology, 2018, (12): 51-53.

[25] Fang Zhengjun, Li Jing, Wu Feng, Chen Jianfang, Yang Hai, A Comprehensive Basic Chemistry Experiment Based on the Integration of Scientific Research and Teaching. Laboratory research and exploration, 2019, (5): 160-163.

[26] Han Xi, Liu Yuansheng, Ma Nan, Study on the construction of applied practice courses under the background of science and education integration, Computer Education, 2018, (10): $22-25+29$.

[27] Fang Hongjun, Guo Xiujing, Relationship between Integration of Science and Education and the innovative talent cultivation in Applied Universities, Economist, 2019, (3): 169-1702.

[28] Wen Hui, Jin Jicheng, Guo Yudong, Integration of Science and Education promoting the innovative talent cultivation, Chinese University Science \& Technology, 2019, (3): 55-56.

[29] Li Jianchun, Liu Xinyi, The Problem and Solution on Integration of Science and Education. Journal of Ningbo Institute of Education, 2020, (3): 1-4+83.

[30] Cao Xiaoyu, Research on Model and Countermeasure of Innovative Talents Cultivation Based on Integration of Science and Education. Higher Agricultural Education, 2018, (6): 22-26.

[31] Huang Chongxing, Xu Shupei, Huang Lijie, Innovative engineering talent training mode of science and education integration. Journal of Higher Education, 2019, (17): 37-39.

[32] Liu Bo, Li Li, Zhao Rong, The Exploration and Practice of Talent Training Mode with Deep Integration of Scientific Research and Teaching. Coal Higher Education, 2019, (2): 86-91.

[33] He Yuhai, Chen Yongzhi, Yang Zhiyong, Chen Jinsong, Research and practice of marine engineering and science disciplines innovative talents cultivation model based on the collaborative innovation and integration of science and education. Research and Practice of Higher Education, 2016, (2): $23-28+76$.

[34] Wang Da-shen, Liu Xiao-mei, Qiao Qingli, Deep integration of scientific research and education: a new innovative talents training mode for biomedical engineering program. Medical and Health Equipment, 2020, (2): 87-90.

[35] Li Yongjian, Liu Dongbo, Zhang Bi, He Hong, Xiao Peng, Reform and Research on the Training Model of Engineering Applied Innovative Talents Based on the Integration of Science and Education. Science and Education Guide (last ten days), 2019, (5): 39-40+56.

[36] Yang Yu, Bai Jisong, Ji Xxuanyu, Tian Ye, Yang Lu, The cultivation mode of applied innovative talent based on the Integration of Science and Education, Comparative Study of Cultural Innovation, 2020, (13): 8-9.

[37] Dong Ming, Shang Yan, He Ying, Tang Dawei, Liu Xiaohua, $\mathrm{Mu}$ Lin, Construction of new talent cultivation mode under the Integration of Science and Education, Research in Higher Education of Engineering, 2019, (S1): 51-252+261. 
[38] Ding Weixin, Peng Yahui, Gui Guorong, Investigation of the undergraduate talent training mode with the Integration of Science and Education from the visual threshold of Collaborative innovation, Contemporary Education Research and Teaching Practice, 2018, (11): 92-94.

[39] Li Maoguo, Zhou Hongfang, Zhu Zhengwei, Current Status and Countermeasures of the Teaching Model United with Researching and Teaching. Research on Higher Engineering Education, 2017, (4): 58-62.

[40] Wang Dehua, Fu Yu-chen, Xue Peng-xiang, Zhu Ya-min, Song Daxia, Exploration and Practice of Science-education Integration Model of College Mathematics in Emerging Engineering Education. Education and Teaching Forum, 2020, (39): $315-317$.

[41] Bai Shuqin, Hasibagen, Teaching mode with the Integration of Science and Education and the cultivation of the practical ability of innovation and entrepreneurship, Journal of Chifeng University (Natural Science Edition). 2019, (9): 161-162.

[42] Han Yali, Zhang Yubo, Study on the teaching mode with the Integration of Science and Education, China Metallurgical Education. 2019, (6): 27-29.

[43] Gong Qindi, Teaching mode under the background of the Integration of Science and Education, Chinese University Science \& Technology. 2015, (6): 45-46.

[44] Lai Lifei, Hu Guoqi, Bao Mingdong, Xu Jinfu, Wang Jinzhi, Theory-practice Integrated Teaching Mode for Materials Majors Based on Integration of Science and Education. Journal of Ningbo Institute of Technology, 2018, (3): 84-89

[45] Yang Zijiang, Wang Fei, $\mathrm{Xu}$ Yan, Investigation of the innovative teaching mode from the visual threshold of the Integration of Science and Education-with an example of design major, Chinese University Science \& Technology. 2018, (9): 52-53.

[46] Tang Yanchuan, Tao Peiling, Shen Mingxue, Liu Dejia, Hu Yong, Zhao Longzhi, The investigation of the innovative teaching mode under the education system of Integration of Science and Education- with an example of materials science and engineering major, Education Modernization. 2019, (86): 163-164.

[47] Qu Xia, Song Xiaozhou, Th e College Famous Teachers' Conception and Action in Integrating Research and Teaching-Based on comparative analysis of famous teachers' and ordinary teachers' questionaires. Research on Higher Education in China, 2016, (6): 97-104.

[48] Qu Xia, Huang Lu, An Investigation and Reflection on Faculty's Acceptance and Practice in Integrating Research and Teaching. Research on Higher Engineering Education, 2016, (4): 83-89.

[49] Zhou Guangli, Huang Lu, Why don't Undergraduates Welcome Advanced Teaching Ideas? Research on Higher Engineering Education, 2016, (2): 48-56.
[50] Liu Bo, Zhu Chenwei, Li li, Liu Nan, Reform Practice of Research-oriented Undergraduate Education Based on the Concept of Integrating Scientific Research and Education. Contemporary Educational Theory and Practice, 2019, (6): 1-4.

[51] Chen Jun, Upholding the concept of Integration of Science and Education to promote the knowledge innovation capability in university, Chinese University Science \& Technology, 2015, (Z1): 4-8.

[52] Zhong Xiangqiang, Liu Caixia, Jing Panpan, Zhang Benxue, Research on Concept Identification and Practice Investigation of Integration of Research and Teaching. Journal of Xichang University (Natural Science Edition), 2018, (3): 103-106+128.

[53] Lin Yanhong, Progress of the concept of Integration of Science and Education and the empirical research, Chinese University Science \& Technology, 2015, (5): 26-27.

[54] Zhang Xiaohui, A brief comment on the cultivation of the concept of Integration of Science and Education in higher education, China Adult Education, 2016, (20): 90-91.

[55] Bai Yan, Ren Zengyuan, Sun Li, The restructure of first class undergraduate education under the Integration of Science and Education, Chinese University Science \& Technology, 2019, (8): 50-53.

[56] Zhou Guangli, Jiang Jiale, Wang Sunyu, Lu Guodong, Educational Value of Research in Universities-The Dilemma of Research-Education Integration and Adjustment of Public Policy. Research on Higher Engineering Education, 2018, (1): 88-94.

[57] Liu Ji'an, Sheng Xiaoguang, Dynamics, Predicament and Breakthrough of Integration of Research and Education: A Case Study of the University of Chinese Academy of Sciences. Research on Higher Education in China, 2020, (11): 26-30.

[58] Zhang Jielong, Wang Junyu, Li Ling, A Research on the Degree of Integration in the Integration of Scientific Research and Education-A Case Study by Taking the Material Science of UCAS as an Example. Information Engineering, 2020, (5): 100-108.

[59] Wang Qingyan, Zhang Huadong, Liu Wei, Study on internal governance in university with the Integration of science and Education, Management Observer, 2018, (11): 108-109.

[60] Wang Fan, Gao Zhen, Investigation of the mode of Integration of science and Education under the background of double first-class construction, Economic \& Trade, 2018, (3): 26-27.

[61] Wu Hongfu, System and Practice of Integration of Research and Teaching in World"s First-class Universities: The Experience of Canterbury University. Journal of Hebei Normal University (Education Science Edition), 2020, (1): 59-66.

[62] Zhang Wei, Zhuang Yixue, Zhou Xiangyu, Mao Di, "Integration and Innovation of Science and Education in the Age of Big Science" and the 14th International Symposium on Development Strategy of Science and Education, Research in Higher Education of Engineering, 2020, (2): 197-200. 